\title{
Study Regarding The Introduction of The Concept "IAAF Kids' Athletics" in The Primary School in Physical Education Lessons
}

\author{
Ababei Cătălina ${ }^{1^{*}}$ \\ 1 “Vasile Alecsandri" University of Bacău, Marasesti 157, 600100, Romania
}

Keywords: athletics, pupils, primary school

\begin{abstract}
The International Amateur Athletic Federation (IAAF) promoted in 2001 a new concept of athletics competition for children. The new concept represents the promotion of athletics as a game, all events being performed as team races or relay races. The points for all of the technical events (jumping, throwing) are calculated by adding each team member's performance. Considering the athletics are present in the school curriculum in all forms of education, this research started from the working hypothesis stating that the implementation of the strategy promoted by the concept "IAAF Kids' athletics" in the primary school physical education lessons could contribute to a major change in the children's understanding and practice of track and field events and to a much faster integration of all pupils. At the end of the research, the concept of team work was received very well by the pupils, the children forming real teams.
\end{abstract}

\section{Introduction}

Athletics is a discipline encountered in the school curricula (according to MEC-SNEE) in all education levels and cycles (MEC 2000). Unfortunately, even though it is a sport without any "pretensions" in regards to its practice conditions and materials, lately it has lost much of its attractiveness. In school, pupils are more interested in recreational activities than of an activity in which top performance is predominant, that is why the reevaluation of the teaching methods of athletics in school becomes an increasingly important aspect (Barbu et al. 1994). The lack of attractiveness of athletics was noticed also by Wall and Murray (1994), who states that track and field events are not very motivating. Another expert, Hirtz (1996), states that actually the way in which athletics are taught is at fault, not the sport itself. Considering this, a new approach of teaching athletics, at least in primary school, would be a new chance in reinstating track and field events among the children's preferences (Debesse, 1970). The same can be said also of the assessment in physical education, an aspect commentated by Brau-Antony (2005). Starting from the mentioned aspects, this author believes that what the International

\footnotetext{
*E-mail: catalinaa_compte@yahoo.fr;
} 
Amateur Athletic Federation (IAAF) promoted in 2001, which is a new concept of children's athletics competition, could be borrowed also by physical education teachers to apply it during their lessons (Wilmore \& Costill, 2005). One year later, the same international body created a practical guide, comprising both the rules regarding the organization of athletics competitions for children, and recommendations about their training. The strategy of the new concept consists in the practice of athletics as a game, all events being performed as team races or relay races. The points for all of the technical events (jumping, throwing) are calculated by adding each team member's performance.

\section{Materials and Methods}

The main objective of the research was to contribute to the improvement of the teaching methods used during physical education lessons, more precisely, of what the contents of the school curricula foresees for athletics.

The purpose of the research was to study primary school children in regards to the strategy of the introducing in the athletics themed lessons of the concept promoted by the International Amateur Athletic Federation (IAAF KID `S ATHLETICS), that could have applicability in children who do not choose to practice athletics during their extracurricular hours.

The research started from the hypothesis stating that: the strategy of the introducing the concept "IAAF Kids' athletics" in the physical education lessons could influence positively the pupils' social interaction as well as their performance level during the assessment challenges.

The tasks of the research were to choose the subjects, to apply the assessment challenges, to analyze and interpret the data, to write the paper.

Research subjects. Initially, this author wanted for this concept to be applied in at least three schools in Bacau, but unfortunately the support was given for only one school. In this context, there is no pretension in regards to the value of the results of the study; however this author believes that a future research in all schools of the city could highlight more clearly the usefulness and effectiveness of the concept. The subjects of the study were the fourth grade pupils from the "Alecu Russo" School of Bacau (Table 1).

Research methods. This research used the following methods: the pedagogical observation, the mathematical-statistical method of analyzing and interpreting the data, the testing method, the graphical representation method.

\section{Results and Discussions}

Development of the research The applicative intervention consisted in borrowing the concept presented in the "IAAF Kid`s Athletics" guide, for working with teams.

Thus, the fourth grade pupils from the "Alecu Russo" School of Bacau were divided into 5 mixed teams of 4 pupils each (Table 2). 
Table 1. The fourth grade pupils from the "Alecu Russo" School of Bacau

\begin{tabular}{ccccc}
\hline Name & Birth year & $\begin{array}{c}\text { Height } \\
(\mathrm{m})\end{array}$ & $\begin{array}{c}\text { Weight } \\
(\mathrm{Kg})\end{array}$ & $\begin{array}{c}\text { Span } \\
(\mathrm{m})\end{array}$ \\
\hline A. I. & 2006 & 1.44 & 32 & 1.37 \\
C. R. & 2007 & 1.36 & 33 & 1.31 \\
C. R. & 2006 & 1.43 & 37 & 1.39 \\
C. M. & 2006 & 1.46 & 34 & 1.42 \\
G. D. & 2006 & 1.37 & 29 & 1.36 \\
H. C. & 2006 & 1.38 & 32 & 1.38 \\
H. A. & 2004 & 1.50 & 43 & 1.43 \\
M. G. & 2006 & 1.44 & 37 & 1.38 \\
M. A. M. & 2006 & 1.45 & 33 & 1.41 \\
M. A. & 2006 & 1.42 & 31 & 1.39 \\
M. A. & 2006 & 1.47 & 43 & 1.50 \\
N. M. & 2006 & 1.38 & 37 & 1.35 \\
N. S. & 2006 & 1.40 & 45 & 1.38 \\
P. D. & 2006 & 1.41 & 59 & 1.44 \\
R. F. & 2006 & 1.42 & 33 & 1.38 \\
S. I. & 2006 & 1.35 & 27 & 1.35 \\
V. S. & 2006 & 1.38 & 34 & 1.38 \\
V. D. & 2006 & 1.51 & 32 & 1.55 \\
V. A. & 2006 & 1.38 & 33 & 1.32 \\
D. A. & 2007 & 1.35 & 49 & 1.36 \\
\hline
\end{tabular}

Table 2. The teams of the fourth grade pupils from the "Alecu Russo" School "of Bacău

\begin{tabular}{cc}
\hline Team name & Team components \\
\hline Bees (A) & A. I. \\
Bees (A) & C. M. \\
Bees (A) & M. G. \\
Bees (A) & M. AD. \\
Frogs (B) & G. D. \\
Frogs (B) & H. A. \\
Frogs (B) & N. M. \\
Frogs (B) & V. S. \\
Beetles (C) & C. RA. \\
Beetles (C) & C. RO. \\
Beetles (C) & H. C. \\
Beetles (C) & P. D. \\
Dinosaurs (D) & M. A. \\
Dinosaurs (D) & N. S. \\
Dinosaurs (D) & S. I. \\
Dinosaurs (D) & V. D. \\
Elephants (E) & D. A. \\
Elephants (E) & M. A. M. \\
Elephants (E) & R. F. \\
Elephants (E) & V. AL. \\
\hline
\end{tabular}

Each team chose a name (Bees, Frogs, Beetles, Dinosaurs, and Elephants), this way the pupils felt they belonged to a group. During the challenges, the 
rankings were done by adding the performances of each team member. Each pupil has participated as a member of a team. Each one of them has contributed individually to the result of the team. Thus, the concept that each participant has value was highlighted. The challenges were adapted according to the demands of the fourth grade curricula.

In order to observe the effectiveness of this concept, the pupils were tested in the same challenges twice, one time individually (Table 3), when their performance did not affect the result of the team, and one time as a team (Table 4). The differences between the individual and the team progress are presented in Table 5.

As it can be seen in Table 3, the pupils' results during the relay challenge (individual results) are between $19.13 \mathrm{sec}$ and $26.97 \mathrm{sec}$, the average being of 22.84 seconds. In regards to the standing long jump, the results are between $0.80 \mathrm{~m}$ and $1.75 \mathrm{~m}$, the average being of $1.26 \mathrm{~m}$.

Table 3. The individual results of the pupils during the $9 \times 5 \mathrm{~m}$ relay and the standing long jump challenges

\begin{tabular}{cccc}
\hline No. & Name & 9x5m relay (sec) & Standing long jump (m) \\
\hline $\mathbf{1}$ & A. I. & 22.74 & 1.30 \\
$\mathbf{2}$ & C. M. & 21.85 & 1.45 \\
$\mathbf{3}$ & M. G. & 25.57 & 1.10 \\
$\mathbf{4}$ & M. AD. & 21.78 & 1.50 \\
$\mathbf{5}$ & G. D. & 19.74 & 1.60 \\
$\mathbf{6}$ & H. A. & 24.14 & 1.00 \\
$\mathbf{7}$ & N. M. & 21.48 & 1.20 \\
$\mathbf{8}$ & V. S. & 21.71 & 1.10 \\
$\mathbf{9}$ & C. RA. & 21.17 & 1.15 \\
$\mathbf{1 0}$ & C. RO. & 26.97 & 1.20 \\
$\mathbf{1 1}$ & H. C. & 19.34 & 1.30 \\
$\mathbf{1 2}$ & P. D. & 24.27 & 1.00 \\
$\mathbf{1 3}$ & M. A. & 20.48 & 1.75 \\
$\mathbf{1 4}$ & N. S. & 24.35 & 1.50 \\
$\mathbf{1 5}$ & S. I. & 19.13 & 1.10 \\
$\mathbf{1 6}$ & V. D. & 22.18 & 1.20 \\
$\mathbf{1 7}$ & D. A. & 24.21 & 0.90 \\
$\mathbf{1 8}$ & M. A. M. & 22.15 & 1.20 \\
$\mathbf{1 9}$ & R. F. & 22.36 & 0.80 \\
$\mathbf{2 0}$ & V. AL. & 23.18 & 1.15 \\
AVERAGE & & $\mathbf{2 2 . 8 4}$ & $\mathbf{1 . 2 6}$ \\
\hline & & &
\end{tabular}

The individual results for the teams during the same challenges are presented in Table 4. In this case, the pupils' results for the relay challenge are between 16.58 sec and $23.55 \mathrm{sec}$, the average being of $20.83 \mathrm{sec}$, while for the standing long jump, the worst result was of $1.10 \mathrm{~m}$, and the best one of $1.85 \mathrm{~m}$, the average being of $1.35 \mathrm{~m}$. 
Table 4. The team results of the pupils during the 9x5m relay and the standing long jump challenges

\begin{tabular}{cccc}
\hline Team & Name & 9x5m relay & Standing long jump \\
\hline A & A. I. & 22.61 & 1.35 \\
A & C. M. & 20.65 & 1.50 \\
A & M. G. & 22.54 & 1.30 \\
A & M. AD. & 18.75 & 1.70 \\
B & G. D. & 17.65 & 1.65 \\
B & H. A. & 21.75 & 1.25 \\
B & N. M. & 20.51 & 1.30 \\
B & V. S. & 20.10 & 1.25 \\
C & C. RA. & 20.23 & 1.18 \\
C & C. RO. & 21.27 & 1.30 \\
C & H. C. & 19.30 & 1.50 \\
C & P. D. & 22.65 & 1.15 \\
D & M. A. & 20.33 & 1.85 \\
D & N. S.. & 22.25 & 1.40 \\
D & S. I. & 16.58 & 1.25 \\
D & V. D. & 21.41 & 1.30 \\
E & D. A. & 23.55 & 1.10 \\
E & M. A. M. & 20.88 & 1.30 \\
E & R. F. & 20.48 & 1.30 \\
E & V. AL. & 22.57 & 1.25 \\
Average & & $\mathbf{2 0 . 8 3}$ & $\mathbf{1 . 3 5}$ \\
\hline
\end{tabular}

Table 5. Differences between the individual and the team progress

\begin{tabular}{cccccccc}
\hline Team & Name & $\begin{array}{c}\text { 9x5m } \\
\text { relay (sec) }\end{array}$ & & $\begin{array}{c}\text { Difference } \\
\text { (sec.) }\end{array}$ & $\begin{array}{c}\text { Standing long } \\
\text { jump (m) }\end{array}$ & $\begin{array}{c}\text { Difference } \\
\text { (m) }\end{array}$ \\
\hline & & Individual & Teams & & Individual & Teams & \\
\hline A & A. I. & 22.74 & 22.61 & 0.13 & 1.30 & 1.35 & 0.05 \\
A & C. M. & 21.85 & 20.65 & 1.2 & 1.45 & 1.50 & 0.05 \\
A & M. G. & 25.57 & 22.54 & 3.03 & 1.10 & 1.30 & 0.20 \\
A & M. AD. & 21.78 & 18.75 & 3.03 & 1.50 & 1.70 & 0.20 \\
B & G. D. & 19.74 & 17.65 & 2.09 & 1.60 & 1.65 & 0.05 \\
B & H. A. & 24.14 & 21.75 & 2.39 & 1.00 & 1.25 & 0.25 \\
B & N. M. & 21.48 & 20.51 & 0.97 & 1.20 & 1.30 & 0.10 \\
B & V. S. & 21.71 & 20.10 & 1.61 & 1.10 & 1.25 & 0.15 \\
C & C. RA. & 21.17 & 20.23 & 1.48 & 1.15 & 1.18 & 0.03 \\
C & C. RO. & 26.97 & 21.27 & 5.7 & 1.20 & 1.30 & 0.10 \\
C & H. C. & 19.34 & 19.30 & 0.04 & 1.30 & 1.50 & 0.20 \\
C & P. D. & 24.27 & 22.65 & 2.07 & 1.00 & 1.15 & 0.15 \\
D & M. A. & 20.48 & 20.33 & 0.15 & 1.75 & 1.85 & 0.10 \\
D & N. S.. & 24.35 & 22.25 & 2.1 & 1.50 & 1.40 & 0.5 \\
D & S. I. & 19.13 & 16.58 & 2.55 & 1.10 & 1.25 & 0.15 \\
D & V. D. & 22.18 & 21.41 & 0.77 & 1.20 & 1.30 & 0.10 \\
E & D. A. & 24.21 & 23.55 & 0.66 & 90 & 1.10 & 0.20 \\
E & M. A. M. & 22.15 & 20.88 & 1.27 & 1.20 & 1.30 & 0.10 \\
E & R. F. & 22.36 & 20.48 & 1.88 & 80 & 1.30 & 0.50 \\
E & V. AL. & 23.18 & 22.57 & 0.61 & 1.15 & 1.25 & 0.10 \\
Average & & $\mathbf{2 2 . 8 4}$ & $\mathbf{2 0 . 8 3}$ & $\mathbf{1 . 6 8}$ & $\mathbf{1 . 2 6}$ & $\mathbf{1 . 3 5}$ & $\mathbf{0 . 1 6}$ \\
\hline
\end{tabular}


For a better visualization of the results and especially of the differences between the two performances, Table 5 presents the results recorded by the pupils during the individual assessment, the team assessment and, of course, the difference between the two results.

As seen in Table 5, the pupils' results during the team assessment are clearly superior to their initial ones, when each pupil's result was not counted for the team. In this sense, the average results are more than eloquent. If during the first assessment, the average for the relay challenge was of $22.84 \mathrm{sec}$, during the second assessment the average decreased by 2.01 sec. Each pupil has recorded a progress in both challenges.

Figures 1 and 2 present the results recorded by the fourth graders individually and their individual results as part of a team.

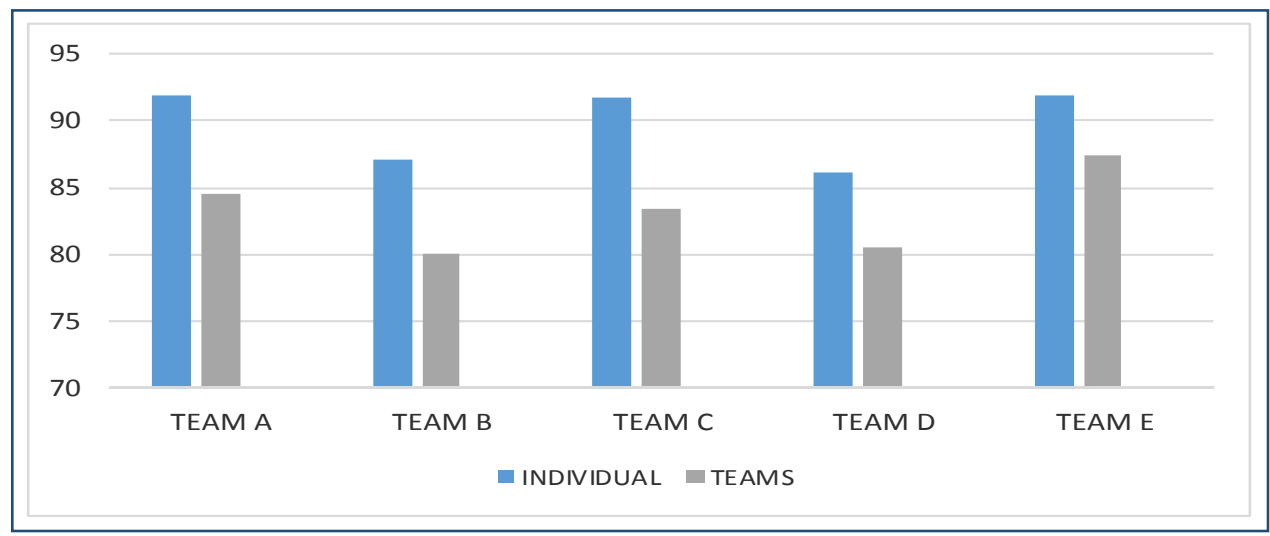

Figure 1. The results recorded by the pupils during the relay challenge, expressed in seconds

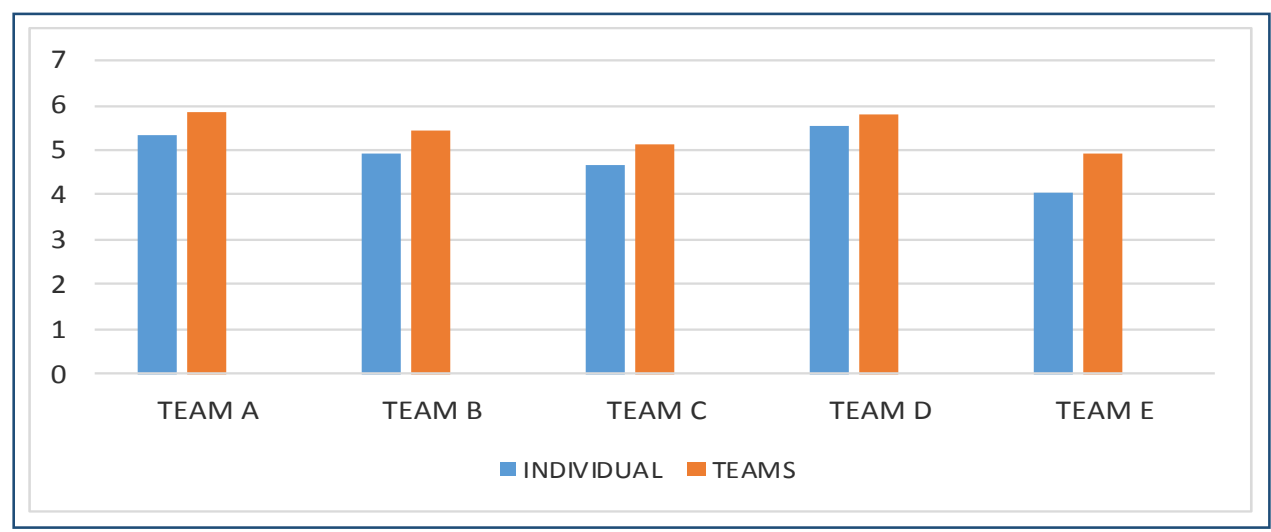

Figure 2. The results recorded by the pupils during the standing long jump challenge, expressed in meters

\section{Discussions}

Unfortunately, the results recorded in this study cannot be compared with other results, because this strategy has not been applied yet at this age, in schools. 
Another version of this strategy has been applied by Gorgan (2014), who in her Ph.D. paper has worked, at the beginning of her study, with the experimental group (during the training process) on teams.

\section{Conclusions}

The study confirmed the working hypothesis stating the strategy of the introducing the concept "IAAF Kids' athletics" in the physical education lessons could influence positively the pupils' social interaction as well as their performance level during the assessment challenges, as follows:

- the significant differences recorded during individual and team assessments explains the pupils' emulation and desire to participate as actively as possible in the physical education lesson.

- the children's desire to work even when they were sometimes injured or excused medically fully justifies the value of the new strategy promoted by the concept "IAAF KID`S ATHLETICS".

The concept of team work was received very well by the pupils, at the end of the research the children forming real teams. Based on the observations made during the breaks, it can be said that the spirit of fairness and helping each other went beyond the 50 minutes of the physical education lessons.

From this point of view, this author believes that one of the major objectives of this discipline was achieved, namely the increase of the attractiveness of the lessons and of the integration of all children in the group, each of them feeling that they belong to a group, of which he or she wanted to be the best.

The advantage of this instruction method was that it has allowed each team to win at least once per lesson, which has proven once again that the competition spirit in a playful form can have great benefits for the development of the pupils' personalities.

\section{References}

1. BRAU-ANTONY, St. (2005). L'évaluation en EPS : concepts et contributions actuelles, Paris: Éd. Actio;

2. BARBU, H., POPESCU, E., \& SERBAN, F. (1994). Activităţi de joc şi recreativ distractive, Bucuresti: Didactică şi Pedagogică ;

3. DEBESSE, M. (1970). Psihologia copilului de la naştere la adolescentăă, Bucureşti: Edit Didactică şi Pedagogică;

4. GORGAN, C. (2014). Strategii de dezvoltare a capacității de efort aerob în probele de semifond la nivel de copii, Teză de doctorat, (Unpublished doctoral dissertation).UNEFS București, Romania;

5. HIRTZ, P. (1996). Die Attraktivität der Leichtathletik in der Schule erhöhen In: Körpererziehung, Heft 4 S. $122-141$;

6. MEC. (2000). Ghidurile metodologice de aplicare a programelor de educatie fizică şi sport, București: MEC;

7. WALL, J., \& MURRAY, N. (1994). Children and Movement. Physical Education in Elementary School, UK: Brown and Benchmark; 
8. WILMORE, J.H., \& COSTILL, D.L. (2005). Physiology of Sport and Exercise: 3rd Edition, UK: Ed. Human Kinetics;

9. IAAF. (2001). Kids' athletics - a practical guide, file://C:/Documents\%20and\%20Settings/User/My\%20Documents/Downloads /IAAF\%20Kids.pdf.

\title{
Studiu Privind Introducerea Conceptului "IAAF Kids' Athletics" in Lecțiile de Educație Fizică din Învățamantul Primar
}

\author{
Ababei Cătălina ${ }^{1}$ \\ 1Universitatea "Vasile Alecsandri" din Bacau, Calea Marasesti 157, 600615, România
}

Cuvinte cheie: atletism, elevi, primar

\section{Rezumat}

Federaţia Internaţională de Atletism Amator (IAAF) a promovat în anul 2001 un nou concept de competiţie atletică pentru copii. Conceptul nou promovat reprezintă promovarea atletismului într-o atmosferă de joc, toate probele fiind realizate sub forma ştafetelor sau a curselor în echipă. În toate probele tehnice (sărituri, aruncări) clasamentele sunt obţinute prin adăugarea performanţelor fiecărui membru al echipei. Având în vedere faptul că atletismul este prezent în curricula şcolară la toate ciclurile de învăţământ, prezentul studiu a plecat de la ipoteza de lucru conform căreia, implementarea strategiei de promovare a conceptului „Kids athletics IAAF” în lecţiile de educaţie fizică la elevii din ciclul primar ar contribui la o schimbare majoră în înțelegerea şi practicare probelor atletice de către şcolarii mici şi la o integrare mult mai rapidă a tuturor elevilor în colectiv. În urma efectuării cercetării, conceptul de lucru în echipă a fost receptat foarte bine de către elevi, formându-se adevărate echipe.

\section{Introducere}

Atletismul este o disciplină prezentă în curricula școlară (cf. MEC-SNEE) la toate nivele și ciclurile de învățământ (MEC 2000). Din păcate, deși este o disciplină sportivă fără "pretenții”" mari în ceea ce privește condițiile de practicare și materialele necesare, în ultimul timp și-a pierdut foarte mult din atractivitate. În școală elevii sunt mai interesaţi mai mult de activitatea de recreere decât de o activitate în care să predomine performanța, și în acest context reevaluarea modului de predare a atletismului în școală devine un aspect din ce în ce mai stringent (Barbu et al., 1994). Lipsa atractivității atletismului în școală a fost remarcat și de Wall and Murray (1994), care afirma că probele atletice sunt prea puțin motivante. Un alt specialist al domeniului, Hirtz (1996) afirma că, de fapt modul de predare al atletismului este deficitar și nu disciplina sportivă. In acest context, considerăm că o nouă abordare a predării atletismului, cel puțin la nivelul claselor primare ar fi o nouă șansă în readucerea probelor atletice în preferința copiilor (Debesse, 1970). In aceeași manieră se pune și problema evaluării în educație fizică, aspect despre care a scris 
Brau-Antony (2005). Plecând de la aspectele mentionate anterior, considerăm că ceea ce a promovat Federaţia Internaţională de Atletism Amator (IAAF) în anul 2001, respectiv un nou concept de competiţie atletică pentru copii, ar putea fi preluat și de către profesorii de educație fizică pentru a-1 aplica în lecțiile de educație fizică (Wilmore \& Costill, 2005). Un an mai tîrziu, acelaşi organism internaţional, a elaborat un ghid practic care cuprindea atât regulile privind organizarea competiţiilor atletice pentru copii, cât şi recomandări referitoare la modul de pregătire al copiilor. Stategia, noului concept promovat, constă în practicarea atletismului într-o atmosferă de joc, toate probele fiind realizate sub forma ştafetelor sau a curselor în echipă. În toate probele tehnice (sărituri, aruncări) clasamentele sunt obţinute prin adăugarea performanţelor fiecărui membru al echipei.

\section{Material şi metode}

Obiectivul principal al cercetării a fost acela de a contribui la îmbunătățirea metodelor de predare în cadrul lecţiilor de educaţie fizică, respectiv a conţinuturilor curriculei şcolare prevăzute la atletism.

Scopul cercetării a fost de a studia la copiii din ciclul primar strategia introducerii în lecțiile tematice de atletism a conceptului promovat de Federația Internațională de Atletism Amator (IAAF KID'S ATHLETICS), care ar putea avea aplicabilitate la copiii care care nu aleg să practice atletismul în programul extrașcolar.

Cercetarea a pornit de la ipoteza că strategia introducerii conceptului de "atletism pentru copii IAAF" în lecțiile de educație fizică ar putea influența pozitiv interacțiunile sociale ale elevilor și nivelul lor de performanță în timpul probelor de evaluare.

Sarcinile cercetării au constat în stabilirea subiecților, aplicarea probelor de evaluare, prelucrarea şi interpretarea datelor, redactarea lucrării.

Subiecţii cercetării. Inițial am dorit ca acest concept să fie aplicat la cel puțin trei școli din municipiul Bacău, dar din păcate am obținut sprijinul pentru implementare doar la o școală. În acest context nu avem pretenția de a emite judecăți de valoare asupra rezultatelor cercetării, dar considerăm că o cercetare viitoare la nivelul tuturor școlilor din municipiu, ar evidenția mult mai pregnant utilitatea și eficiența conceptului.

Subiecţii prezentului studiu l-au reprezentat elevii clasei a IV-a de la Şcoala Gimnazială "Alecu Russo" din Bacău (Tabel 1).

Metode de cercetare. În realizarea cercetării am folosit următoarele metode de cercetare: observaţia pedagogica, metoda matematică statistică de interpretare și prelucrare a datelor, metoda testelor, metoda grafică.

\section{Rezultate și discuții}

Desfăşurarea cercetării. Intervenţia aplicativă a constat în preluarea de la conceptul prevăzut în ghidul "IAAF Kid's Athletics", a lucrului pe echipe.

Astfel, elevii clasei a IV -a din cadrul Şcolii Gimnaziale "Alecu Russo" din Bacău au fost împărtiţi în 5 echipe mixte de câte 4 elevi (Tabel 2). 
Tabel 1. Elevii clasei a IV-a de la Şcoala Gimnazială "Alecu Russo” din Bacau

\begin{tabular}{ccccc}
\hline Numele și prenumele & Anul nașterii & $\begin{array}{c}\text { Înălțimea } \\
(\mathbf{m})\end{array}$ & $\begin{array}{c}\text { Greutatea } \\
(\mathbf{K g})\end{array}$ & $\begin{array}{c}\text { Anvergura } \\
\text { (m) }\end{array}$ \\
\hline A. I. & 2006 & 1.44 & 32 & 1.37 \\
C. R. & 2007 & 1.36 & 33 & 1.31 \\
C. R. & 2006 & 1.43 & 37 & 1.39 \\
C. M. & 2006 & 1.46 & 34 & 1.42 \\
G. D. & 2006 & 1.37 & 29 & 1.36 \\
H. C. & 2006 & 1.38 & 32 & 1.38 \\
H. A. & 2004 & 1.50 & 43 & 1.43 \\
M. G. & 2006 & 1.44 & 37 & 1.38 \\
M. A. M. & 2006 & 1.45 & 33 & 1.41 \\
M. A. & 2006 & 1.42 & 31 & 1.39 \\
M. A. & 2006 & 1.47 & 43 & 1.50 \\
N. M. & 2006 & 1.38 & 37 & 1.35 \\
N. S.. & 2006 & 1.40 & 45 & 1.38 \\
P. D. & 2006 & 1.41 & 59 & 1.44 \\
R. F. & 2006 & 1.42 & 33 & 1.38 \\
S. I. & 2006 & 1.35 & 27 & 1.35 \\
V. S. & 2006 & 1.38 & 34 & 1.38 \\
V. D. & 2006 & 1.51 & 32 & 1.55 \\
V. A. & 2006 & 1.38 & 33 & 1.32 \\
D. A. & 2007 & 1.35 & 49 & 1.36 \\
\hline
\end{tabular}

Tabel 2. Echipele cu elevii clasei a IV-a de la Şcoala Gimnazială "Alecu Russo" din Bacău

\begin{tabular}{cc}
\hline Numele Echipei & Componenta echipei \\
\hline Albinute (A) & A. I. \\
Albinute (A) & C. M. \\
Albinute (A) & M. G. \\
Albinute (A) & M. AD. \\
Broscute (B) & G. D. \\
Broscute (B) & H. A. \\
Broscute (B) & N. M. \\
Broscute (B) & V. S. \\
Carabusi (C) & C. RA. \\
Carabusi (C) & C. RO. \\
Carabusi (C) & H. C. \\
Carabusi (C) & P. D. \\
Dinozauri (D) & M. A. \\
Dinozauri (D) & N. S.. \\
Dinozauri (D) & S. I. \\
Dinozauri (D) & V. D. \\
Elefanti (E) & D. A. \\
Elefanti (E) & M. A. M. \\
Elefanti (E) & R. F. \\
Elefanti (E) & V. AL. \\
\hline
\end{tabular}

Fiecare echipă si-a ales un nume (Albinuțe, Broscuțe, Carabuși, Dinozauri 
sau Elefanți), astfel incît elevii au simțit apartenența la un grup.

La probele evaluate, clasamentele au fost obţinute prin adăugarea performanţelor fiecărui membru al echipei. Toţi elevii au participat ca membrii ai echipei. Fiecare dintre ei au contribuit individual la rezultatul echipei. Astfel s-a întărit conceptul că fiecare participant are valoare. Probele au fost adaptate in funcţie de cerinţele programei pentru clasa a-IV-a. Pentru a observa eficienţa acestui concept, elevii au fost testati la acelaşi probe de două ori, respectiv, o dată individual (Tabel 3) când performanța lor nu afecta rezultatul echipei şi o dată în cadrul echipei (Tabel 4). Diferențele dintre evoluția individuală și cea din cadrul echipei sunt redate in Tabelul 5.

După cum se observă din tabelul 3, performanțele elevilor la proba de navetă (rezultate individuale), se înscriu între 19,13 sec și 26,97sec., media fiind de $22,84 \mathrm{sec}$. În ceea ce privește săritura în lungime de pe loc, performanțele se înscriu între $0,80 \mathrm{~m}$ și $1,75 \mathrm{~m}$, media fiind de $1,26 \mathrm{~m}$.

Rezultatele individuale însumate în cadrul echipelor la aceleași probe, le prezentăm în tabelul 4. În acest caz, rezultatele elevilor la proba de navetă se înscriu între 16,58 sec si 23,55 sec, media fiind de 20,83sec., iar la săritura în lungime cea mai mică performanță a fost de $1,10 \mathrm{~m}$, iar cea mai mare de $1,85 \mathrm{~m}$, media fiind de $1,35 \mathrm{~m}$

Tabel 3. Rezultate individuale ale elevilor la proba de naveta $9 \times 5 \mathrm{~m} \mathrm{si}$ saritura in lungime fara elan

\begin{tabular}{cccc}
\hline Nr.crt. & Nume & Naveta 9x5m (sec) & Lungime de pe loc (m) \\
\hline $\mathbf{1}$ & A. I. & 22.74 & 1.30 \\
$\mathbf{2}$ & C. M. & 21.85 & 1.45 \\
$\mathbf{3}$ & M. G. & 25.57 & 1.10 \\
$\mathbf{4}$ & M. AD. & 21.78 & 1.50 \\
$\mathbf{5}$ & G. D. & 19.74 & 1.60 \\
$\mathbf{6}$ & H. A. & 24.14 & 1.00 \\
$\mathbf{7}$ & N. M. & 21.48 & 1.20 \\
$\mathbf{8}$ & V. S. & 21.71 & 1.10 \\
$\mathbf{9}$ & C. RA. & 21.17 & 1.15 \\
$\mathbf{1 0}$ & C. RO. & 26.97 & 1.20 \\
$\mathbf{1 1}$ & H. C. & 19.34 & 1.30 \\
$\mathbf{1 2}$ & P. D. & 24.27 & 1.00 \\
$\mathbf{1 3}$ & M. A. & 20.48 & 1.75 \\
$\mathbf{1 4}$ & N. S. & 24.35 & 1.50 \\
$\mathbf{1 5}$ & S. I. & 19.13 & 1.10 \\
$\mathbf{1 6}$ & V. D. & 22.18 & 1.20 \\
$\mathbf{1 7}$ & D. A. & 24.21 & 0,90 \\
$\mathbf{1 8}$ & M. A. M. & 22.15 & 1.20 \\
$\mathbf{1 9}$ & R. F. & 22.36 & 0,80 \\
$\mathbf{2 0}$ & V. AL. & 23.18 & 1.15 \\
$\mathbf{M E D I A ~}$ & & $\mathbf{2 2 , 8 4}$ & $\mathbf{1 , 2 6}$ \\
\hline
\end{tabular}


Tabel 4. Rezultatele elevilor in cadrul echipelor la proba de naveta 9x5 m și săritura in lungime fără elan

\begin{tabular}{cccc}
\hline Echipa & Nume & Naveta 9x5m & Lungime de pe loc \\
\hline A & A. I. & 22.61 & 1.35 \\
A & C. M. & 20.65 & 1.50 \\
A & M. G. & 22.54 & 1.30 \\
A & M. AD. & 18.75 & 1.70 \\
B & G. D. & 17.65 & 1.65 \\
B & H. A. & 21.75 & 1.25 \\
B & N. M. & 20.51 & 1.30 \\
B & V. S. & 20.10 & 1.25 \\
C & C. RA. & 20.23 & 1.18 \\
C & C. RO. & 21.27 & 1.30 \\
C & H. C. & 19.30 & 1.50 \\
C & P. D. & 22.65 & 1.15 \\
D & M. A. & 20.33 & 1.85 \\
D & N. S. & 22.25 & 1.40 \\
D & S. I. & 16.58 & 1.25 \\
D & V. D. & 21.41 & 1.30 \\
E & D. A. & 23.55 & 1.10 \\
E & M. A. M. & 20.88 & 1.30 \\
E & R. F. & 20.48 & 1.30 \\
E & V. AL. & 22.57 & 1.25 \\
Media & & $\mathbf{2 0 . 8 3}$ & $\mathbf{1 . 3 5}$ \\
\hline
\end{tabular}

Tabel 5. Diferentele dintre evolutia individuala si cea din cadrul echipei

\begin{tabular}{cccccccc}
\hline Echipa & Nume & $\begin{array}{c}\text { Naveta } \\
\text { 9x5m (sec) }\end{array}$ & & $\begin{array}{c}\text { Diferenta } \\
\text { (Sec.) }\end{array}$ & $\begin{array}{c}\text { Lungime de pe loc } \\
\text { (m) }\end{array}$ & $\begin{array}{c}\text { Diferenta } \\
\text { (m) }\end{array}$ \\
\hline & & Individual & Echipe & & Individual & Echipe & \\
\hline A & A. I. & 22.74 & 22.61 & 0.13 & 1.30 & 1.35 & 0.05 \\
A & C. M. & 21.85 & 20.65 & 1.2 & 1.45 & 1.50 & 0.05 \\
A & M. G. & 25.57 & 22.54 & 3.03 & 1.10 & 1.30 & 0.20 \\
A & M. AD. & 21.78 & 18.75 & 3.03 & 1.50 & 1.70 & 0.20 \\
B & G. D. & 19.74 & 17.65 & 2.09 & 1.60 & 1.65 & 0.05 \\
B & H. A. & 24.14 & 21.75 & 2.39 & 1.00 & 1.25 & 0.25 \\
B & N. M. & 21.48 & 20.51 & 0.97 & 1.20 & 1.30 & 0.10 \\
B & V. S. & 21.71 & 20.10 & 1.61 & 1.10 & 1.25 & 0.15 \\
C & C. RA. & 21.17 & 20.23 & 1.48 & 1.15 & 1.18 & 0.03 \\
C & C. RO. & 26.97 & 21.27 & 5.7 & 1.20 & 1.30 & 0.10 \\
C & H. C. & 19.34 & 19.30 & 0.04 & 1.30 & 1.50 & 0.20 \\
C & P. D. & 24.27 & 22.65 & 2.07 & 1.00 & 1.15 & 0.15 \\
D & M. A. & 20.48 & 20.33 & 0.15 & 1.75 & 1.85 & 0.10 \\
D & N. S.. & 24.35 & 22.25 & 2.1 & 1.50 & 1.40 & 0.5 \\
D & S. I. & 19.13 & 16.58 & 2.55 & 1.10 & 1.25 & 0.15 \\
D & V. D. & 22.18 & 21.41 & 0.77 & 1.20 & 1.30 & 0.10 \\
E & D. A. & 24.21 & 23.55 & 0.66 & 90 & 1.10 & 0.20 \\
E & M. A. M. & 22.15 & 20.88 & 1.27 & 1.20 & 1.30 & 0.10 \\
E & R. F. & 22.36 & 20.48 & 1.88 & 80 & 1.30 & 0.50 \\
E & V. AL. & 23.18 & 22.57 & 0.61 & 1.15 & 1.25 & 0.10 \\
Media & & $\mathbf{2 2 , 8 4}$ & $\mathbf{2 0 . 8 3}$ & $\mathbf{1 , 6 8}$ & $\mathbf{1 , 2 6}$ & $\mathbf{1 . 3 5}$ & $\mathbf{0 , 1 6}$ \\
\hline
\end{tabular}


Pentru o vizualizare mai bună a performanțelor și mai ales a diferențelor dintre cele două execuții ale elevilor, în tabelul numărul 5 prezentăm rezultatele obținute de elevi la evaluarea individuală, la evaluarea din cadrul echipei și desigur, diferența dintre cele două rezultate.

După cum se observă din datele prezentate in tabelul numărul 5, performanțele elevilor în cadrul evaluării pe echipe sunt net superioare celor înregistrate inițial, când rezultatul fiecărui elev nu era contabilizat pentru echipă. În acest sens, mediile rezultatelor sunt mai mult decât elocvente. Dacă în primul caz, la proba de navetă media rezultatelor a fost de $22,84 \mathrm{sec}$. la prima testare, la a doua media a scăzut cu 2,01 sec. Menționăm aici faptul că fiecare elev a înregistrat un progres, cum de altfel s-a întâmplat și la proba cealaltă.

Prezentăm în continuare rezultatele înregistrate de elevii clasei a IV-a, realizate individual şi în paralel rezultatele individuale realizate în momentul în care performanţa sa, devenea parte a performanţei echipei (Fig. 1 și Fig. 2)

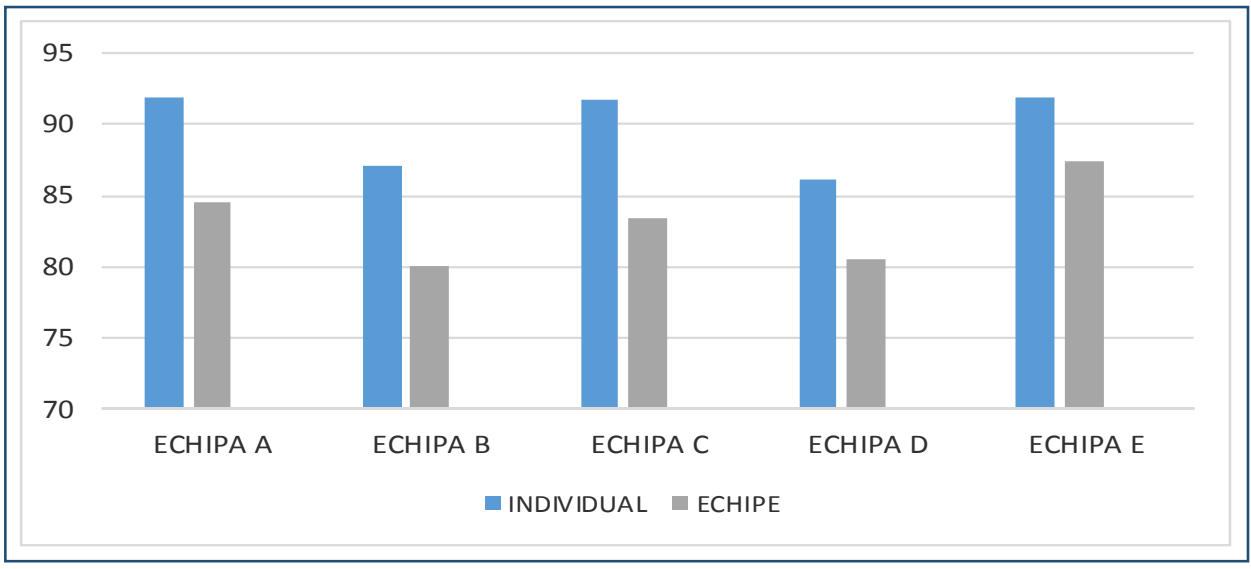

Figura 1. Rezultatele obtinute de elevi la proba de naveta exprimate in secunde acumulate

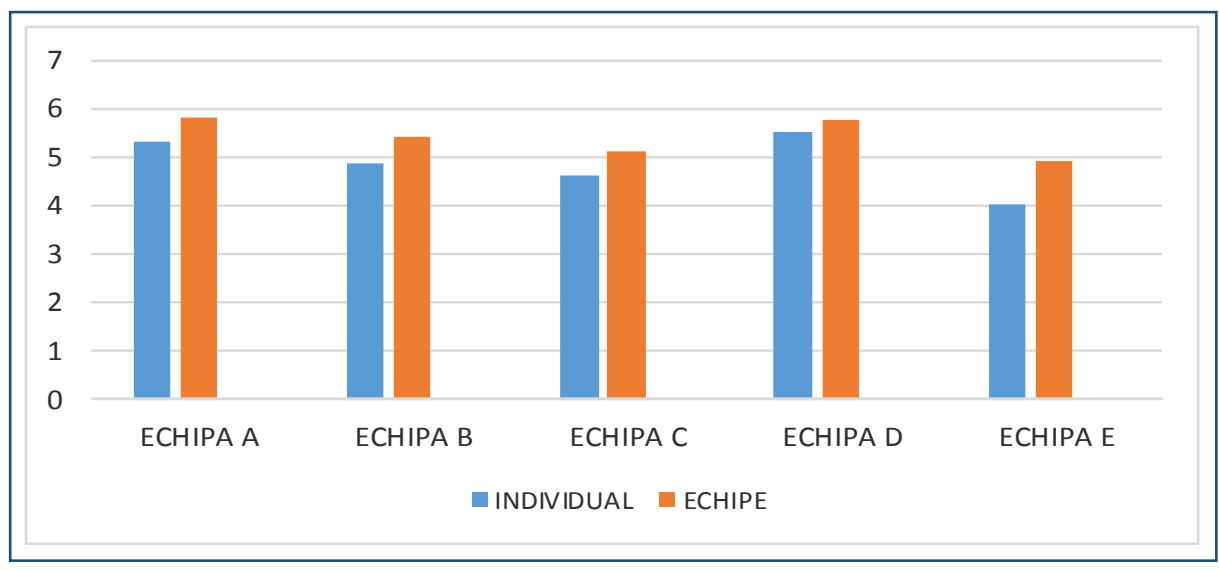

Figura 2. Rezultatele obtinute de elevi la proba de saritura in lungime de pe loc exprimate in metri acumulati 


\section{Discuții}

Din păcate, rezultatele obținute nu le putem compara cu alte rezultate, pentru că strategia nu a mai fost aplicată la această vîrstă, în școală. O altă variană a acestei strategii a realizat-o Gorgan (2014), care în cercetarea efectuată în cadrul tezei de doctorat, a lucrat la debutul studiului, cu grupa experiment (în procesul de atrenament) pe echipe.

\section{Concluzii}

Studiul efectuat ne-a confirmat ipoteza de lucru conform căreia: strategia introducerii conceptului de "atletism pentru copii IAAF" în lecțiile de educație fizică ar putea influența pozitiv interacțiunile sociale ale elevilor și nivelul lor de performanţă în timpul probelor de evaluare în următoarele direcţii:

- diferenţele semnificative înregistrate în momentul testărilor individuale şi a celor înregistrate în cadrul echipei explică emulaţia şi dorinţa de a participa cât mai activ la lecţiile de educaţie fizică;

- dorinţa de a lucra chiar si atunci când elevii erau uneori acccidentaţi sau scutiţi din motive medicale, justifică pe deplin valoarea noii strategii promovate în cadrul noului concept "IAAF KID `S ATHLETICS”.

Conceptul de lucru în echipă a fost receptat foarte bine de către elevi, în urma studiului formându-se adevărate echipe. Din observaţiile efectuate în timpul pauzelor putem afirma că spiritul de întrajutorare şi fair play au depăşit graniţa celor 50 de minute ale lecţiilor de educaţie fizică.

Din acest punct de vedere, considerăm că am indeplinit unul dintre obiectivele majore ale disciplinei, respectiv cel al creșterii atractivităţii lecțiilor și al integrării tuturor elevilor în colectiv, fiecare dintre ei având sentimentul apartenenţei la un grup, grup care îşi dorea să fie cel mai bun.

Avantajul aplicării acestei metode de instruire a permis ca fiecare echipă să fie învingătoare cel puţin o dată pe lecţie, fapt ce a confirmat încă o dată, că spiritul de competiţie sub forma lúdica aduce mari beneficii în formarea personalităţii elevilor. 